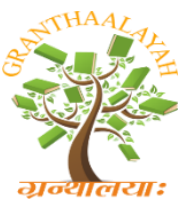

INTERNATIONAL JOURNAL OF RESEARCH GRANTHAALAYAH A knowledge Repository

Social

\title{
REASONING ABILITY AMONG HIGHER SECONDARY STUDENTS
}

\author{
Mrs. P.Kanimozhi ${ }^{* 1}$, Dr.P.Ganesan ${ }^{2}$ \\ ${ }^{* 1}$ Research Scholar (Part-Time), Tamil Nadu Teachers Education University, Karapakkam, \\ Chennai- 600 097, India \\ ${ }^{2}$ Professor and Head, Department of Pedagogical Science, Tamil Nadu Teachers Education \\ University, Karapakkam, Chennai-600 097, India
}

DOI: https://doi.org/10.29121/granthaalayah.v5.i6.2017.2058

\begin{abstract}
The present study is a survey in nature to find out reasoning ability among higher secondary students in Madurai District. The investigator in order to find out reasoning ability among higher secondary students developed and validated a tool for the study. The tool is of a multiple choice type consisting of 50 items. The investigator selected a stratified random sample of 303 higher secondary students for the study. Data were collected from the sample. The data were given appropriate statistical treatments. The findings revealed that among higher secondary students $61.38 \%$ of them are poor in reasoning ability, $21.45 \%$ of them are average in reasoning ability, $16.5 \%$ of students are very poor in reasoning ability and only $0.66 \%$ of students are good in reasoning ability. There exists a positive correlation between mathematical achievement and reasoning ability. There is no significant difference in reasoning ability among higher secondary students in terms of gender. It can be interpreted that both male and female students are uniform in reasoning ability.
\end{abstract}

Keywords: Reasoning Ability; Higher Secondary Students; Mathematics Achievement; Gender; Correlation.

Cite This Article: Mrs. P.Kanimozhi, and Dr.P.Ganesan. (2017). "REASONING ABILITY AMONG HIGHER SECONDARY STUDENTS." International Journal of Research - Granthaalayah, 5(6), 471-475. https://doi.org/10.29121/granthaalayah.v5.i6.2017.2058.

\section{Introduction}

\section{What is reasoning?}

Reasoning is what we do when we take information that we are given, compare it to what we already know, and then come up with a conclusion. While much of our ability to reason is innate, these skills can be taught and improved upon. Reasoning skills often happen subconsciously and within seconds. However, sometimes we need to think things through to reach a conclusion when 
we are presented with a tough question or situation. Reasoning skills are essential to day-to-day life: we use them to make choices among possible options, to distinguish between positive and negative situations, to decide how to approach a problem and resolve it, and much more. The following equation helps us to understand how it all works:

\section{Given Information + Knowledge $=$ Reasoned Conclusion}

We have to use reasoning skills all the time in the real world. For example, say you get invited to a family function, but you also have an important school assignment to finish. This requires reasoning, since you must consider the two choices, trying to balance family with schooling. Also, we are often presented with situations that force us to make moral decisions between right and wrong. Your friends may ask you to do something that you know you probably shouldn't do, such as smoking or drinking. In this case, you must reason between the harmful effects and the moral choice vs. pleasing your friends and having 'fun', as they may call it!

Verbal reasoning means understanding and reasoning using concepts framed in words. It aims at evaluating ability to think constructively, rather than at simple fluency or vocabulary recognition.

In non-verbal reasoning (NVR) diagrams are used for expressing the ideas instead of using numbers and words. Non-verbal reasoning shows a series of figures arranged in a sequence or pattern and then the missing figure is required to be identified or the next in the sequence. Because the non-verbal reasoning questions are believed to be the best indicators of general intelligence.

\section{Objectives of the Study}

1) To find out reasoning ability among higher secondary students.

2) To find out the correlation between mathematical achievement and reasoning ability among higher secondary students.

3) To find out the significant difference in reasoning ability among higher secondary students in terms of gender.

\section{Hypotheses}

1) The reasoning ability among higher secondary students is average.

2) There is no correlation between mathematical achievement and reasoning ability among higher secondary students.

3) There is no significant difference in reasoning ability among higher secondary students in terms of gender.

\section{Terms and Definitions}

Reasoning Ability - refers to what we do when we take information that we are given, compare it to what we already know, and then come up with a conclusion.

Higher Secondary students - refers to the students at $11^{\text {th }}$ and $12^{\text {th }}$ std. 


\section{Delimitations and Scope of the Study}

The study is confined only to higher secondary students in Madurai. The subgroups identified for the study was gender.

The findings of the study will reveal the level of reasoning ability among higher secondary students in Madurai only. It cannot be over generalized and considered as an overall reflection of reasoning ability among higher secondary students in other cities. However it may give an idea about reasoning ability among higher secondary students.

\section{Planning of the Multiple Choice Items}

The researcher studied the concept of reasoning ability in detail and decided to have 50 items. Each item has 4 alternate answers. The candidate has to choose any one item. The items are of multiple choice types.

\section{Establishing Reliability of the Tool}

\section{Test and Retest Method}

The test was administered among the 20 students and re-administered among the same 20 after a gap of 15 days. The comparative performance and deviation were analyzed. The deviation is negligible. Hence the tool is assumed to be having reliability. Thus the reliability was ensuring the tryout.

\section{Establishing Validity of the Tool}

The face and content validity was established for this tool. The face and content validity was checked with experts in the field of competitive exams coaching. The concurrent validity was checked by repeated administration of the tool. According to Garret, H.E (1967, P.365) the index of reliability is also taken as a measure of validity.

\section{Scoring}

The tool consists of 50 reasoning items. Each item will get I mark. The total marks will be 50 .

\section{Sample}

The investigator has followed stratified random sampling method for the Present study. There were 303 students taken for the study. The strata were Government, Government- Aided and Self-Finance higher secondary schools in Madurai.

\section{Analysis and Interpretation of Data}

\section{HYPOTHESIS 1:}

The reasoning ability among higher secondary students is average. 
Table 1: Percentage Analysis of Reasoning Ability among Higher Secondary Students

\begin{tabular}{|l|l|l|l|}
\hline Score Percentage & Description & No. of Students & Percentage \\
\hline $81-100$ & Very Good & 0 & 0 \\
\hline $61-80$ & Good & 2 & 0.66 \\
\hline $41-60$ & Average & 65 & 21.45 \\
\hline $21-40$ & Poor & 186 & 61.38 \\
\hline $0-20$ & Very Poor & 50 & 16.5 \\
\hline & Total & 303 & 100 \\
\hline
\end{tabular}

It is evident from Table 1, that $61.38 \%$ of higher secondary students are Poor in reasoning ability. $21.45 \%$ of students are Average in reasoning ability. 16.5\% of students are Very Poor in reasoning ability. $0.66 \%$ of students are good in reasoning ability. No one is in the very good level in reasoning ability out of 303 students in the sample selected for the study.

It may be concluded from the above table $61.38 \%$ of higher secondary students are Poor in reasoning ability. $21.45 \%$ of students are Average in reasoning ability. $16.5 \%$ of students are Very Poor in reasoning ability. $0.66 \%$ of students are good in reasoning ability.

\section{HYPOTHESIS 2:}

There is no correlation between mathematical achievement and reasoning ability among higher secondary students.

Table 2: Correlation between Mathematical Achievement and Reasoning Ability among Higher Secondary Students

\begin{tabular}{|l|l|l|l|l|l|}
\hline S.No. & Variable & $\mathbf{N}$ & $\mathbf{D f}$ & "r" & $\begin{array}{l}\text { Significance } \\
\text { level 0.05 }\end{array}$ \\
\hline \multirow{2}{*}{1} & $\begin{array}{l}\text { Mathematical } \\
\text { Achievement }\end{array}$ & \multirow{2}{*}{303} & 301 & 0.17951 & .088 \\
\cline { 2 - 6 } & Reasoning Ability & & & & \\
\hline
\end{tabular}

It is evident from Table 2 that ' $r$ ' value is 0.179 .It exceeds the critical value of .088 at 0.05 levels. Hence it can be interpreted that there exists significant positive correlation between mathematical achievement and reasoning ability among higher secondary students. It can be surmised that the mathematical achievement and reasoning ability are positively correlated. Hence the hypothesis stated as there is no correlation between mathematical achievement and reasoning ability is rejected. It can be interpreted that there exists positive correlation between mathematical achievement and reasoning ability.

\section{HYPOTHESIS 3:}

There is no significant difference in reasoning ability among higher secondary students in terms of gender. 
Table 3: Mean, S.D. 'T' Values of Reasoning Ability among Higher Secondary Students in Terms of Gender

\begin{tabular}{|l|l|l|l|l|l|l|}
\hline Sex & $\mathbf{N}$ & Mean & SD & 't' Value & $\begin{array}{l}\text { Critical } \\
\text { Value }\end{array}$ & $\begin{array}{l}\text { Level of } \\
\text { Significance }\end{array}$ \\
\hline Male & 84 & 12.09 & 4.83 & & $\begin{array}{l}1.960 \quad \text { for } \\
\text { degree of } \\
\text { freedom of } \\
301 \quad \text { at } \\
0.05 \text { level }\end{array}$ & $\begin{array}{l}\text { No } \\
\text { Significance }\end{array}$ \\
\hline Female & 219 & 13.23 & 4.39 & 0.062 & & \\
\hline
\end{tabular}

It is evident from Table 3. that the obtained ' $t$ ' value is 0.062 . It is lesser than the critical value of 1.960 for degrees of freedom of 301 at 0.05 level. It is not significant. Hence, the hypothesis stated as there is no significant difference in reasoning ability among higher secondary students in terms of gender is accepted.

It may be concluded from the above table that there is no significant difference in reasoning ability among higher secondary students in terms of gender. It can be interpreted that both male and female students are uniform in reasoning ability.

\section{Findings of the Study}

The following are the findings of the study:

1) The findings revealed that among higher secondary students $61.38 \%$ of them are poor in reasoning ability, $21.45 \%$ of them are average in reasoning ability, $16.5 \%$ of students are very poor in reasoning ability, and only $0.66 \%$ of students are good in reasoning ability among higher secondary students.

2) There exists a positive correlation between mathematical achievement and reasoning ability.

3) There is no significant difference in reasoning ability among higher secondary students in terms of gender. It can be interpreted that both male and female students are uniform in reasoning ability.

\section{References}

[1] Best, J.W., Research in Education, New Delhi, Prentice Hall of India, 1977

[2] Buch, M.N., Fourth Survey of Research in Education, New Delhi, NCERT, 1991

[3] Good, C.V., Dictionary of Education, New York, MC Graw Hill Book Company, 1959

[4] Grewal, P.S. Method of Statistical Analysis, New Delhi, Sterling Publishers Private Limited, 1990.

[5] Kochher, K.S. Pivotal Issues in Indian Education, New Delhi, Sterling Publishers Private Ltd., 1981

[6] Malhotra, Deepak. "The Desire to Win: The Effects of Competitive Arousal on Motivation and Behavior." Organizational Behavior and Human Decision Processes 111 (2010): 139-146

[7] http://study.com/academy/lesson/reasoning-definition-examples-quiz.html

[8] https://en.wikipedia.org/wiki/Verbal_reasoning

[9] https://en.wikipedia.org/wiki/Non_Verbal_reasoning 